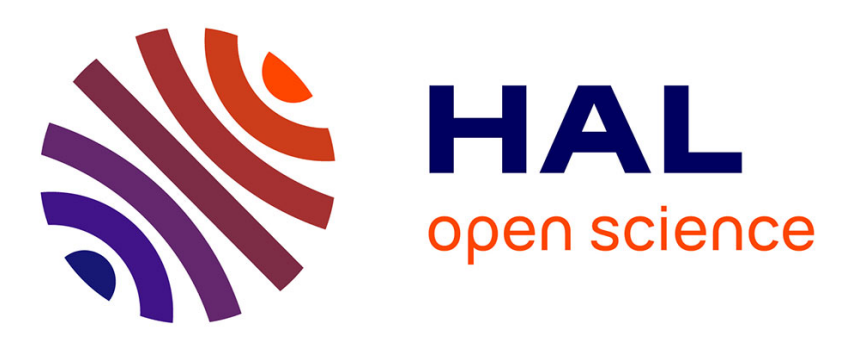

\title{
Thin bone sample assessment using ultrasonic transmitted signals based on wavelet processing method
}

Rui Zheng, Emmanuelle Lefevre, Cécile Baron, Philippe Lasaygues

\section{To cite this version:}

Rui Zheng, Emmanuelle Lefevre, Cécile Baron, Philippe Lasaygues. Thin bone sample assessment using ultrasonic transmitted signals based on wavelet processing method. 2013 International Congress on Ultrasonics, May 2013, Singapore. pp.1-5. hal-00947409

\author{
HAL Id: hal-00947409 \\ https://hal.science/hal-00947409
}

Submitted on 18 Feb 2014

HAL is a multi-disciplinary open access archive for the deposit and dissemination of scientific research documents, whether they are published or not. The documents may come from teaching and research institutions in France or abroad, or from public or private research centers.
L'archive ouverte pluridisciplinaire HAL, est destinée au dépôt et à la diffusion de documents scientifiques de niveau recherche, publiés ou non, émanant des établissements d'enseignement et de recherche français ou étrangers, des laboratoires publics ou privés. 


\title{
THIN BONE SAMPLE ASSESSMENT USING ULTRASONIC TRANSMITTED SIGNALS BASED ON WAVELET PROCESSING METHOD
}

\author{
RUI ZHENG \\ Laboratory of Mechanics and Acoustics, CNRS, 31, Chemin Joseph Aiguier, \\ Marseille, 13402, France \\ EMMANUELLE LEFEVRE \\ Institute of Movement Sciences, ISM - UMR 7287 CNRS/Aix-Marseille-University, \\ Marseille, France \\ CECILE BARON \\ Institute of Movement Sciences, ISM - UMR 7287 CNRS/Aix-Marseille-University, \\ Marseille, France \\ PHILIPPE LASAYGUES \\ Laboratory of Mechanics and Acoustics, CNRS, 31, Chemin Joseph Aiguier, \\ Marseille, 13402, France
}

\begin{abstract}
The wavelet-based processing (WBP) method based on Meyer-Jaffard algorithm was implemented to simultaneously determine the thickness and velocity of thin cortical bone samples. Two groups of bovine samples were measured by one pair of immersion transducers with nominal frequency $2.25 \mathrm{MHz}$. The WBP method was used to estimate the times of flight (TOF) of two pulses contained by one transmitted signal. The mean relative error of thickness measurement is $6.13 \%$. The mean velocities and their standard deviation for two different groups are $3399 \pm 131$ $\mathrm{m} / \mathrm{s}$ and $3502 \pm 182 \mathrm{~m} / \mathrm{s}$, which lead to the average relative errors from the pulse-mode method of $8.38 \%$ and $11.15 \%$ respectively. The results demonstrate that the WBP method is able to measure thin bone samples whose thickness is comparable or even less than ultrasound wavelength and provides the potential to assess more reliable initial models for the further imaging process.
\end{abstract}

\section{INTRODUCTION}

Imaging techniques based on the inversion theories can be implemented to reconstruct internal structures of long bones such as tibia and fibula. Two types of reconstruction experiments along different directions have been attempted on bone imaging. Ultrasonic computed tomography (UCT) focusing on the radial measurement around the middle shaft of bones are applied in vitro to image the cross-section of femurs of children and estimate the cortical thickness using a 2D-ring antenna and mechanical and electronic steering systems (Lasaygues and Lefebvre, 2001; Lasaygues, 2006). While Zheng (2011) employs similar techniques and methods, yet acquires zero-offset data along the axial direction on the bone surfaces, reconstructs the image of sagittal plane of long bones, and particularly estimates the thickness of top cortical layer. According to Lippmann and Schwinger (1950), the initial models determined before the inversion procedures can greatly influence the inversion results during imaging process. Therefore the pre-determined velocity and thickness of cortex more close to real quantities of the parameters will provide better 
initial models (i.e. the background parameters), and moreover lead to better reconstruction results of bone imaging (Lasaygues and Le Marrec, 2008).

Simultaneous determination on thickness and velocity has been developed and applied on other materials, e.g. porous composites (Hsu and Hughes, 1992) and solid plates (Kim et al, 2003), using high frequency ultrasound such as 5 or $10 \mathrm{MHz}$. The wavelet-based processing (WBP) method based on Meyer-Jaffard algorithm were then derived to measure the thickness and velocity of cortical bone samples at the same time with applying only one ultrasonic transmitted signal using low frequency of $1 \mathrm{MHz}$ (Loosvelt and Lasaygues, 2011). The goal of this study is to investigate the feasibility and robustness of the WBP method under transmission mode on assessing thin bone samples, whose thickness are approximate or smaller than the ultrasound wavelength.

\section{METHODS AND EXPERIMENTS}

\section{Wavelet-based processing (WBP) method}

As indicated by Loosvelt and Lasaygues (2011), the times of flight (TOF) corresponding to different pulses in the same transmitted signal can be detected by taking correlations between the cross-correlation function of the signal and a pre-determined analyzing pattern. With the two estimated TOFs and the reference velocity and direct reference transmission time in medium (water in this case), the thickness (e) and velocity $\left(\mathrm{V}_{\mathrm{e}}\right)$ of the object can be calculated using equations as below

$\mathrm{e}=\mathrm{V}_{\text {ref }}\left[\mathrm{t}_{0}-\frac{3 \mathrm{t}_{1}-\mathrm{t}_{2}}{2}\right]$

and

$\mathrm{V}_{\mathrm{e}}=\mathrm{V}_{\text {ref }}\left[\frac{2 \mathrm{t}_{0}-3 \mathrm{t}_{1}+\mathrm{t}_{2}}{\mathrm{t}_{2}-\mathrm{t}_{1}}\right]$

where, $V_{\text {ref }}$ is the reference velocity of ultrasound in water, $t_{0}$ is the traveling time from transmitter to receiver in water only (reference transmission time), $t_{1}$ is the transmission time with sample in between, and $t_{2}$ is the multiple transmission time with one reflection in sample (indicated as (Loosvelt and Lasaygues, 2011)).

\section{Samples and experiments}

Two groups of bovine cortical bone samples were measured by one pair of immersion transducers (Imasonic ${ }^{\circledR}$ ) with nominal frequency $2.25 \mathrm{MHz}$. The thickness of 14 samples measured by caliper is ranged from 0.93 to $2.32 \mathrm{~mm}$, approximately corresponding to 0.6 to 1.5 wavelengths referring to cortical bone tissue. The samples in Group 1 marked as numbers (1-6) were cut parallel to the radial direction, while the samples in Group 2 marked as letters $(\mathrm{A}-\mathrm{H})$ were cut parallel to the transverse direction. Due to the different orientation of bone matrix, the bone samples from two groups reveal slightly different acoustic properties.

Figure 1 shows the experimental setup for the measurement in transmission mode. The sample was located at the focal spots of transducers $(\sim 150 \mathrm{~mm}$ from the transducer). With application of function generator (TTI ${ }$ TGA1241), the WBP method was applied to estimate the TOFs for two pulses $\left(t_{1}\right.$ and $\left.t_{2}\right)$ contained in the same transmitted signal. The TOFs were then used to calculate thickness and velocity of the samples using Eq.(1) and (2). The high-frequency transducers with nominal frequency $7 \mathrm{MHz}$ and $10 \mathrm{MHz}$ were also employed in pulse-mode method for the 
comparison between different ultrasonic methodologies. As demonstrated in (Loosvelt and Lasaygues, 2011), the pulse-mode method uses two reflection and one transmission shots to eventually achieve the thickness and velocity, separately.

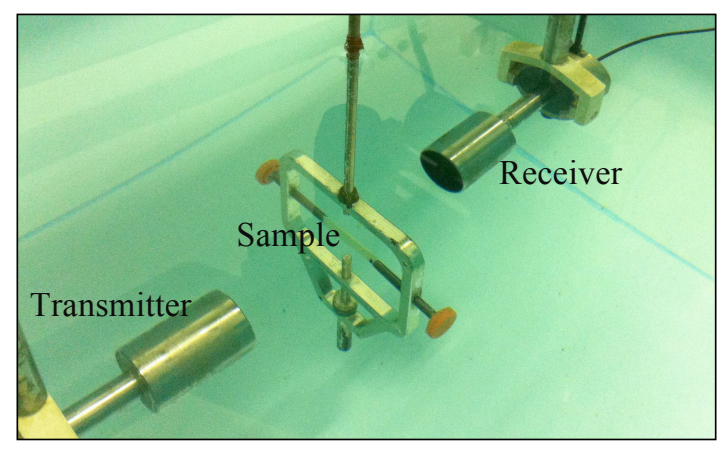

Figure 1. Experimental setup for the transmission measurement of thin bone samples.

\section{RESULTS AND DISCUSSIONS}

Table 1\&2 illustrate the results of thickness and velocity measurement for all 14 samples, and the relative errors (denoted as "error" in the tables) were calculated by dividing the difference between ultrasonic measurements (from the pulse-mode or WBP transmission methods) and physical measurements (thickness from caliper or velocity from pulse-mode method using $7 \mathrm{MHz}$ transducers ) by physical results.

For the thickness measurement showed in Table 1, the errors are literally increased from less than $1 \%$ up to $14 \%$ with the decrease of sample thickness; especially when the thickness is comparable or less than $1 \mathrm{~mm}(\sim 0.6$ wavelength), the errors incredibly grow up to more than $10 \%$ due to the inaccuracy of TOF detection resulting from the interference between approaching pulses in the transmitted signal. The mean relative error of all samples is $6.13 \%$ referring to the physical measurement, which is a bit greater than the results from the $7 \mathrm{MHz}$ pulse-mode method $(4.96 \%)$ yet much smaller than the results from $10 \mathrm{MHz}(13.67 \%)$. The reason for this phenomenon can be contributed to the influence on measurement accuracy and precision by the frequency of transducers. The higher frequency will result in higher precision, yet the results will be greatly affected by noises at the same time, for example the larger errors in $10 \mathrm{MHz}$ measurement. In consideration of the lower frequency applied, the WBP method shows equivalent performance as the pulse-mode method using higher frequency such as $7 \mathrm{MHz}$, moreover reduces the impact of low SNR resulting from high frequencies such as $10 \mathrm{MHz}$.

As shown in Table 2, the mean velocities for two different groups are $3399 \mathrm{~m} / \mathrm{s}$ and $3502 \mathrm{~m} / \mathrm{s}$, which lead to the discrepancies from the pulse-mode method using $7 \mathrm{MHz}$ transducers of $8.43 \%$ (referring to $3712 \mathrm{~m} / \mathrm{s}$ of Group 1) and $11.52 \%$ (referring to $3958 \mathrm{~m} / \mathrm{s}$ of Group 2), respectively. The two possible reasons for these misfits are the dispersion in different frequency ranges applied to two methods and the dehydration due to low temperature during preservation between two experiments. On the other respect, the standard deviations (STD) are $131 \mathrm{~m} / \mathrm{s}$ for Group 1 and 182 $\mathrm{m} / \mathrm{s}$ for Group 2, which are both smaller than the results from the pulse-mode method. Moreover, most of the relative errors are ranged from $4 \%$ to $17 \%$ for both groups, and their means are $8.38 \%$ 
and Table 1. Thickness and comparison among different ultrasonic methods and caliper measurement. The errors are calculated by dividing the difference between the ultrasonic measurement and caliper results by caliper results.

\begin{tabular}{|c|c|c|c|c|c|c|c|}
\hline \multirow{2}{*}{ Sample } & \multirow{2}{*}{$\begin{array}{c}\text { Caliper } \\
(\mathrm{mm})\end{array}$} & $\begin{array}{c}\text { Value } \\
(\mathrm{mm})\end{array}$ & Error & $\begin{array}{c}\text { Value } \\
(\mathrm{mm})\end{array}$ & Error & $\begin{array}{c}\text { Value } \\
(\mathrm{mm})\end{array}$ & Error \\
\hline 1 & 2.14 & 2.13 & $0.37 \%$ & 2.21 & $3.41 \%$ & 2.18 & $1.77 \%$ \\
\hline 2 & 1.51 & 1.52 & $0.38 \%$ & 1.81 & $19.87 \%$ & 1.57 & $3.87 \%$ \\
\hline 3 & 2.32 & 2.23 & $4.05 \%$ & 2.62 & $12.70 \%$ & 2.33 & $0.52 \%$ \\
\hline 4 & 1.82 & 1.88 & $3.17 \%$ & 1.97 & $8.18 \%$ & 1.89 & $3.66 \%$ \\
\hline 5 & 1.64 & 1.55 & $5.24 \%$ & 1.70 & $3.54 \%$ & 1.71 & $4.24 \%$ \\
\hline 6 & 1.26 & 1.32 & $4.68 \%$ & 1.35 & $6.61 \%$ & 1.29 & $2.48 \%$ \\
\hline $\mathrm{A}$ & 1.06 & 1.11 & $4.71 \%$ & 1.17 & $10.61 \%$ & 1.21 & $14.08 \%$ \\
\hline $\mathrm{B}$ & 1.51 & 1.60 & $6.08 \%$ & 1.74 & $14.90 \%$ & 1.61 & $6.33 \%$ \\
\hline $\mathrm{C}$ & 0.98 & 1.10 & $12.45 \%$ & 1.50 & $53.44 \%$ & 1.11 & $13.01 \%$ \\
\hline $\mathrm{D}$ & 0.93 & 0.86 & $7.33 \%$ & 1.01 & $9.16 \%$ & 1.04 & $12.14 \%$ \\
\hline $\mathrm{E}$ & 1.33 & 1.39 & $4.74 \%$ & 1.44 & $8.21 \%$ & 1.36 & $2.43 \%$ \\
\hline $\mathrm{F}$ & 1.24 & 1.34 & $8.25 \%$ & 1.37 & $10.84 \%$ & 1.34 & $8.25 \%$ \\
\hline $\mathrm{G}$ & 0.97 & 1.02 & $4.74 \%$ & 1.19 & $22.16 \%$ & 1.06 & $9.58 \%$ \\
\hline $\mathrm{H}$ & 1.29 & 1.33 & $3.19 \%$ & 1.39 & $7.70 \%$ & 1.33 & $3.46 \%$ \\
\hline Mean & & & $4.96 \%$ & & $13.67 \%$ & & $6.13 \%$ \\
\hline
\end{tabular}

Table 2. Velocities and comparison among different ultrasonic measurements. The errors are calculated by dividing the difference between the WBP method and pulse-mode method with $7 \mathrm{MHz}$ by the latter results.

\begin{tabular}{|c|c|c|c|c|c|c|c|c|c|}
\hline \multicolumn{9}{|c|}{ Group 1 } & \multicolumn{5}{c|}{ Group 2 } \\
\hline \multirow{2}{*}{ Sample } & \multirow{2}{*}{$\begin{array}{c}7 \mathrm{MHz} \\
(\mathrm{m} / \mathrm{s})\end{array}$} & \multirow{2}{*}{$\begin{array}{c}10 \mathrm{MHz} \\
(\mathrm{m} / \mathrm{s})\end{array}$} & $\begin{array}{c}\text { Value } \\
(\mathrm{m} / \mathrm{s})\end{array}$ & Error & Sample & $\begin{array}{c}7 \mathrm{MHz} \\
(\mathrm{m} / \mathrm{s})\end{array}$ & $\begin{array}{c}\text { WMHz } \\
(\mathrm{m} / \mathrm{s})\end{array}$ & $\begin{array}{c}\text { Value } \\
(\mathrm{m} / \mathrm{s})\end{array}$ & Error \\
\hline 1 & 3684 & 3732 & 3541 & $3.87 \%$ & $\mathrm{~A}$ & 3927 & 3598 & 3319 & $15.47 \%$ \\
\hline 2 & 3542 & 4052 & 3168 & $10.55 \%$ & $\mathrm{~B}$ & 3603 & 3391 & 3568 & $0.97 \%$ \\
\hline 3 & 3852 & 3479 & 3432 & $10.90 \%$ & $\mathrm{C}$ & 3528 & 2939 & 3306 & $6.29 \%$ \\
\hline 4 & 3645 & 3679 & 3498 & $4.04 \%$ & $\mathrm{D}$ & 4339 & 3338 & 3357 & $22.64 \%$ \\
\hline 5 & 3866 & 3838 & 3352 & $13.29 \%$ & E & 3865 & 3598 & 3533 & $8.59 \%$ \\
\hline 6 & 3684 & 3739 & 3404 & $7.61 \%$ & $\mathrm{~F}$ & 4267 & 3547 & 3521 & $17.49 \%$ \\
\hline & & & & & G & 4062 & 3310 & 3865 & $4.84 \%$ \\
\hline & & & & & H & 4073 & 3537 & 3548 & $12.89 \%$ \\
\hline Mean & 3712 & 3753 & 3399 & $8.38 \%$ & Mean & 3958 & 3407 & 3502 & $11.15 \%$ \\
\hline STD & 125 & 189 & 131 & & STD & 289 & 221 & 182 & \\
\hline
\end{tabular}


$11.15 \%$, respectively. Especially, there is no apparent distinction on the measurement under the condition of various sample thickness. Even with the samples thinner than $1 \mathrm{~mm}$ such as $\mathrm{C}$ and $\mathrm{G}$, the errors can be as small as around 5\%. It indicates that the wavelet-based processing method is a more consistent and robust approach for the velocity estimation.

\section{CONCLUSIONS}

The results demonstrate that the WBP method is able to measure thin bone samples whose thickness is comparable or even less than ultrasound wavelength. The results match well with the mechanical measurement and other ultrasonic methods using high-frequency transducers. However when the thickness is below $1 \mathrm{~mm}$, larger errors are yielded due to the uncertainty of TOF determination. Although there is variance between the WBP and pulse-mode method on velocity estimation, the results are still comparable regarding the different experimental conditions and nominal frequencies. Moreover the results of WBP method are relatively more consistent, which provides the potential to assess a more reliable pre-determined velocity for the further inversion process.

\section{ACKNOWLEDGMENTS}

This research is supported by the French National Research Agency (MALICE Program ANR under Grant No. BS09-032).

\section{REFERENCES}

Hsu D.K. \& Hughes M.S. (1992). "Simultaneous ultrasonic velocity and sample thickness measurement and application in composites", J. Acoust. Soc. Am., 92(2), 669-675.

Kim Y.H, Song S.J. \& Lee J.K. (2003). "Simultaneous measurements of the ultrasonic wave velocity and thickness of a solid plate made from one side of the plate", Meas. Sci. Technol., 14, N13-N16.

Lasaygues P. (2006). "Assessing the cortical thickness of long bone shafts in children, using twodimensional ultrasonic diffraction tomography", Ultrasound in Med.\& Biol, 32(8), 1215-1227.

Lasaygues P. \& Lefebvre J.P. (2001). "Cancellous and cortical bone imaging by reflected tomography", Ultrasonic imaging, 23, 55-70.

Lasaygues P. \& Le Marrec L. (2008). "Ultrasonic reflection tomography vs. canonical body approximation: experimental assessment of an infinite elastic cylindrical tube", Ultrasonic Imaging, 30(1), 29-43.

Lippmann B.A. \& Schwinger J. (1950). "Variational Principles for Scattering Processes. I.", Physical Review, 79(3), 469-480.

Loosvelt M. \& Lasaygues P. (2011). “A wavelet-based processing method for simultaneously determining ultrasonic velocity and material thickness", Ultrasonics, 51, 325-339.

Zheng R. (2011). Ultrasonic imaging and cortical thickness determination of long bones (PhD). University of Alberta, Edmonton, Canada, 